\title{
Pecado personal, perdón y liberación
}

\section{Jon Sobrino \\ Centro de Reflexión Teológica, \\ San Salvador, El Salvador.}

La teologia de la liberación insiste en la existencia y gravedad del pécado histórico, en la posibilidad y urgencia de que sea superado, y en la erradicación histórica del pecado como su superación más adecuada. Con ello se mantiene fiel a lo central de la revelación de Dios, que toma sumamente en serio lo negativo de la historia y affade-como lo más específico suyo- que, sin embargo, hay posibilidad de salvación; y toma en serio la realidad de este mundo, como aquello que da muerte y como lo que esłá clamando por la vida.

La masividad, crueldad y acrecentamiento de este peca to histórico exige que la teologia de la liberación, y toda teología, siga haciendo del pecado histórico y su erradicación algo central. ${ }^{1}$ En este artículo, sin embargo, vamos a tratar también lo que de personal hay en el pecado, y en el perdón como la forma específica de superación del pecado en cuanto personal.

Una razón para abordar el tema podŕa ser contestar a las acusaciones de reduccionismo que se le hacen a la teología de la liberación por lo que toca al pecado. Pero, sobre todo, aquí se aborda el tema porque pecado y perdón son realidades centrales en la revelación y porquc incluso la erradicación del pecado histórico puede ser potenciada por el reconocimiento del propio pecado y la acepración del perdón.

En los tres primeros apartados trataremos del perdón como superación del pecado personal; y en los dos últimos trataremos de su importancia para la liberación histórica. Pcro comencemos con las dificultades hoy existentes en el reconocimiento del propio pecado personal.

\section{Dificultades actuales para el reconocimiento del propio pecado}

De antiguo viene la dificultad de determinar en qué consiste la liberación del pecado, cómo compaginar la afirmación de que con Crisio el pecado está obje- 
tivamente vencido y la apropiación personal de esa victoria. Y en la actualidad, además, existe una dificultad añadida y fundamental: la crisis en el reconocimiento del propio pecado. Si es diffcil determinar en qué consiste la liberación del pecado, más lo será si ni siquiera hay conciencia de él o hay conciencia muy disminuida.

Para describir la actual simación por lo que loca a la conciencia del propio pecado puede decirse, en general, que existe la tendencia a pasar de una visión "omnipecaminosa" de los creyentes a otra "apecaminosa;" de una visión de la vida dominada por el pecado personal o su posibilidad (y relacionada con la condenación etema transcendente como su consecuencia más especffica) a una visión de disminuida responsabilidad personal en las acciones negativas de los seres humanos ( $y$, desde luego, a una visión en la cual no opera seriamente la posibilidad de una condenación eterna).

Ni una ni otra visión, sin embargo, hacen justicia a la revelación de Dios ni a la experiencia de los seres humanos. La primera desfigura gravemente la realidad de Dios que apareció en Jesús; pero la conclusión no debiera ser ni lógica ni experiencialmente la segunda: que los seres humanos pierdan la capacidad de reconocerse como pecadores. No se afirma esto por pura fidelidad formal a la revelación de Dios ni, menos aún, por algún residuo masoquista que fuera inherente a la fe cristiana. Se afirma por la misma honradez con que hay que rechazar la visión omnipecaminosa de la vida. Y se dice, sobre todo, porque es un bien para los seres humanos saberse y reconocerse en su total verdad y un mal el ignorarlo o reprimirlo, porque es un bien edificar sobre la verdad y un mal edificar sobre la mentira. Y es lambién un bien porque desde el reconocimiento del propio pecado la revelación de Dios cobra una luminosidad especifica, el perdón recobra su dimensión de buena noticia para el ser humano, dimensión opacada y ocultada cuando el ser humano no se reconoce tal cual es.

Ciertamente los tiempos no están -ni tienen por qué estar- para que el creyente haga central la pregunta del atormentado Lutero: "como encontrar a un Dios benévolo," aunque esto no implica que hoy sea más fácil responder a la versión secularizada de aquella pregunla: "cómo encontrar a un ser humano benévolo;" o para que el creyente retome la angustia de Pablo: "me complazco en la ley de Dios según el hombre interior, pero advierto otra ley en mis miembros... y me esclaviza a la ley del pecado" (Rom 7,21ss). Los tiempos no parecen estar para este tipo de preocupaciones; pero si desaparecieran wtalmente, desapareceria también la expectativa de "encontrar benevolencia," lo cual no acaece sin merma de lo humano y sin merna del eu-aggelion,una de cuyas dimensiones esenciales es mostrar benevolencia.

Veamos cú́les parecen ser las causas de la dificultad para reconocer el propio pecado personal.

Existe hoy un redescubrimiento de que el pecado -con ser, al menos conccptualmente, algo último negativo- no es lo único que expresa la negati- 
vidad de la historia ni lo único que en la Escritura aparece como negatividad última. Muene, enfermedad, sinsentido, mundo de injusticia generalizada, son también ultimidades negativas que son captadas como tales. Ello lleva -si no, lógicamente, a hacer desaparecer la ultimidad negativa del pecado- sí a relativizarla y a superar la visión omnipecaminosa de la vida como si lo único real y decisivamente negativo fuese el pecado personal. Y para ello encuentra también apoyo en la Escritura: Dios quiere decididamente la liberación de todas esas ulumidades negativas, no sólo la del pecado personal. Dicho en otras palabras, el propio pecado no aparece ya como lo único que confronta al ser humano con la negatividad; y, existencialmente, pueden, además, ser otras negatividades las que más lo afligen. Puede añadirse incluso que ${ }_{2}$ cristianamente, al ser humano se le exige que ponga su mirada y trate de solucionar la ultimidad negativa que somete a los "otros," sin dejarse obsesionar por su "propio" pecado, lo cual, en último icrmino, sería una forma de egocentrismo y no reproduciría —aunque en otro contexto- el excentricismc antropológico y creyente de Pablo: "Quisiera ser yo maldito por la salvación de mis hermanos" (Rom. 9,3).

Esta dificultad es muy verdadera en el mundo actual. Si en el primer mundo pudiera verse el sinsentido de la vida como la mayor de las negatividades - presuponiendo que para el pecado personal siempre puede haber, en úlumo término, una solución-, en el tercer mundo la tragedia de la situación historica hace más que comprensible ver en ella la úllima negatividad -incluso cuando se quiere ver la historia con los ojos de Dios-y hace pasar a otro plano de valores el propio pecado, a no ser que éste se relacione con aquélla.

Parece claro también que el avance de las ciencias ha repercutido en la merma de conciencia del propio pecado. La psicologia tiende a diluir la culpa en complcjos factores del comportamiento humano y avisa de liberarse de culpabilidades exageradas que conducen a neurosis. Las ciencias sociales responsabilizan a las estructuras del pecado objetivo estructural, lo cual tiende a llevar al anominato las responsabilidades personales.

También la teología ha cooperado en este proceso al desechar, con razón, una imagen de Dios, quien en los seres humanos sólo vería pecado o su posibilidad, y una imagen del hombre quien prácticamente quedaría delinido como sujeto apto de pecado. Pero si esta nueva y generalizada visión teológica es sana, hay que reconocer que algunas teologías que han proliferado desde la posguerra, al centrar el pecado en la interioridad del ser humano y definirlo, concentradamente, desde la subjetividad humana, pueden paradójicamente formular con fuerza lo que es pecado, pero debilitan la conciencia de pecado, al no mostrar a éste -en su objetivación histórica - como lo visible y verificable, y, por lo tanto, como aquello de lo cual se puede y debe tener conciencia. Teologías más orientadas desde la subjetividad podrán definir el pecado, con razón y radicalmente, como cerrazón a Dios, no dejarse dar el sentido de la vida por Dios, no depositar la última confianza y esperanza en Dios, etc. Estas teologías unilateralmente existencialistas, personalistas o de la esperanza podrán, pues, formular lo que es pecado, pero con 
dificultad apuntan a pecados reales y verificables, con lo cual al ser humano lc será posible saberse transcendentalmente como pecador, pero le scrá difícil saberse históricamente como pecador; lo cual no ocurre cuando la teología se orienta desde la objetividad y define el pecado, histórica y verificablemente, como aquello que da muerte ( con todas las analogías necesarias).

Otra raíz de la desvalorización de la conciencia de pecado, quizás la más grave desde un punto de vista estrictamente teológico, es la percepción de que pecado es correlativo — para su liberación-a perdón. Pero el perdón, si no se lo entiende como mero acto judicial, no es ni antropológica ni teológicamente logro del ser humano, sino que es don y gracia. Y aquí sí hay una importante dificultad ambiental ciertamente en el primer mundo, pero incluso -aunque no por necesidad, sí como peligro inherente- en las teologías de la praxis.

Con razón la antropología, y también la antropología teológica basada en el evangelio, insiste en la dimensión práxica del ser humano y del crcyentc, en el hacer el reino de Dios. Que esta insistencia sea legítima y neccsaria para no dejar la realidad abandonada a su miseria en nombre de Dios, es evidente, aunque siempre conviene insistir en ello y a ello volveremos después. El peligro está en que la dimensión práxica de la vida del creyente haga ignorar la dimensión de gratuidad de su existencia. Ya veremos cómo la teología de la liberación insiste e intenta compaginar ambas dimensiones de praxis y gratuidad, pero detengámonos ahora en la dificultad tal como se presenta, sobre todo, en el primer mundo.

La impresión que da el primer mundo, estructuralmente hablando, es que no sabe qué hacer con la gratuidad. Su teología seguirá hablando, por necesidad, del don y de la gracia, de que todo comenzó con Dios gratuitamente y todo terminará en Dios gratuitamente. Conceptualmente no puede ignorar el tema de la gratuidad, pero no le es nada fácil integrarla en la realidad histórica porque le faltan mediaciones ambientales para ello y le sobran las contrarias. El primer mundo, en efecto, piensa que ha llegado a ser lo que es como logro suyo, y que eso mismo es sef̂al de que lo logrado es bueno; pero en ello está ausente la misma noción de que para llegar a ser en verdad se necesita también estar abierto al recibir. En su relación con otros mundos, lo más flagrante es, por supuesto, la opresión a que los somete; pero incluso en lo que pudiera concebirse como su relación "positiva" con aquéllos, piensa que sólo le compete dar, no recibir. Dará así unilateralmente - sean cuales fueren sus intereses en ese dar- su civilización, su tecnología, sus capitales, su teología incluso. Pero la mera noción de dorı, del recibir inesperada e inmerecidamente, le es hoy ambientalmente ajena. Está abierto al recibir en la esfera del tener (materias primas, posibilidades de turismo. etc.), pero no en la esfera del ser, en aquella en que se humaniza el ser humano. Esa ausencia ambiental del don y de la gracia para llegar a ser, como personas y como pueblos, hace también muy difícil la aceptación del perdón. Y con ello -paradojica, pero muy lógicamente desde un punto de vista cristiano- el reconocimiento del propio pecado. 
Una última dificultad proviene de la aceptación de la analogía del pecado y, de ahí, de la necesaria tipificación de los pecadores. El Nucvo Testamento y la teología de la libcración recalcan que el analogatum princeps del pecado está en el dar muerte: dar muerte al Hijo de Dios y seguir dando muerte a los hijos de Dios en la historia. Según esta delinición del pecado, la visión más fundamental entre los seres humanos - no sólo desde la historia, sino desde Dios- está entre aquellos que dan muerte y aquellos que la padecen; $y$ ante la gravedad del pecado que da mucrie, los posibles pecados de quienes la padecen tienden, con razón ,a ser relativizados.

Ya en los sinópticos quedan upificados tres tipos de seres humanos a quienes Jesús hace exigencias específicas: los "opresores," los pecadores por antonomasia, a quienes Jesús denuncia y desenmascara y de quienes exige radical conversión consistente en dejar de ser opresores; los "pobres y oprimidos" a quienes Jesús defiende de aquéllos y de quienes exige una metanoia que, en lo fundamental, consiste en el cambio radical de su visión de Dios como quien está en favor de cllos, no en su contra, más la exigencia a superar pecados "regionales" fruto de la debilidad humana; y los "seguidores" a quienes Jesús exige entrega a la misión.

Por lo que loca a la conciencia de pecado, de acuerdo a esta Lipificación, es claro, ayer como hoy, que el pecador-opresor con suma dificultad llega a poseerla (recuérclese que en la presentación de los sinópticos Jesús sólo tuvo éxito con Zaqueo) ${ }^{2}$. Por lo que toca a los pobres son ellos los que, paradójicamente, más mantienen la conciencia de pecado, se deba esto a su religiosidad radicional o a la nucva religiosidad liberadora. Por lo que toca a los seguidores, es claro que en su autoconciencia - con la humildad del caso- piensan estar en el cauce correcto y luchando contra el pecado fundamental que da muerte.

Lo que aquí interesa recalcar es que, comprensiblemente, en presencia del pecado mayor del opresor, padeciéndolo y luchando contra él, se tiende a relativizar los propios pecados. $Y$ aunque los mismos pobres, como hemos afirmado, y los seguidores más honrados reconocen también su propia pecaminosidad, la terrible desproporción entre el pecado que se padece de parte de los opresores y los propios de uno, posce la tendencia a hacer ignorar estos úlumos.

\section{El reconocimiento del pecado personal a través del perdón}

Las dificultades del reconocimiento del propio pecado son, pues, variadas y abundantes; algunas tiene su raíz en cosas a su vez pecaminosas, mientras que otras tienen su raíz en cosas buenas. Pero, sean cuales fueren las dificultades, no es ningún bien para el ser humano no reconocerse en su verdad, que incluye también su ser pecador. Por ello es necesario algún tipo de mystagogía que introduzca en el misterio, no ya de Dios, sino de la propia pequeñez y oscuridad. No se dice esto, por supuesto, para volver a una "leología del chantaje" o para presentar a un "Dios aguafiestas," como denunciaba Bonhoefler, ni para universalizar, sin diferenciar jerarquizadamente, la condición pecaminosa de todo ser 
humano, que llevase a ignorar o a suavizar la trágica maldad del analogarum princeps: dar muerte a los seres humanos.

Desechadas las antiguas mystagogías provenientes de la visión omnipecaminosa (reforzadas con la amenaza de la condenación etema) hay que preguntarse cuál es la mystagogla fundamental desde un punto de vista estrictamente tcológico (sean cuales fueren sus ulteriores concreciones pastorales). Y aunque esto parezca tarea fácil, no lo es ni siquiera metodológicamente. Indudablemente, desde un punto de vista cristiano habrá que recurrtir a la revelación de Dios en busca de la mystagogia, pero con la apertura a dejarnos decir por Dios lo que es pecado y cómo es posible su reconocimiento, sin suponer rutinariamente que eso es cosa ya sabida. Y eso lo afirmarnos porque "pecado" no es una realidad puramente regional, en principio ya conocida adecuadamente; es más bien una realidadlimite, que, por supuesto, se objetiva en lo concreto. Si en las deliniciones formales teologales se dice que pecado es "ofensa a Dios" o "trangresión de la voluntad de Dios," el "Dios" con que se relaciona el pecado otorga cierta indefinibilidad a la misma realidad del pecado hasta que el mismo Dios se manifieste $y$, en concreto, se manifieste en relación con el pecado.

No quiere esto decir, por supuesto, que nada sepamos del pecado y su gravedad con anterioridad a la revelación de Dios. Lo que sí quiere decir es que, con anterioridad a ella, poseemos conceptos previos, necesarios e importantes, pero no definitivos, análogamente a lo que se afirma del concepto de "humanidad" y "divinidad" en la cristología. De ambas cosas tenemos conceptos previos, pero qué sean en verdad sólo se sabe desde la manifestación en Jesús de la verdadera humanidad y de la verdadera divinidad, que concretan y modifican los conceptos previos. Algo análogo hay que decir del pecado: para saber qué es y qué hacer con él, hay que estar activamente abiertos a lo que Dios dice del pecado y a lo que hace con el pecado; y hay que estar abiertos a la sorpresa que eso pueda producir.

Veamos, pues, muy sucintamente lo que la revelación de Dios en Jesús dice del pecado personal. Por una parte dice que los seres humanos somos capaces de pećado, capaces de tener un corazón de piedra y de oprimir y llegar a dar muerte a los demás hasta el grado de llegar a dar muerte al Hijo de Dios. Dice que poseemos la innata tendencia a ocultarnos a nosotros mismos y a reprimir nuestra verdad de pecadores (lo que Pablo universaliza en Rom 1, 18ss), hasta el punto de poder llegar a pensar que damos culto a Dios cuando enviamos a la muerte al hermano ( $c f r$. In 16,2). Dice que producimos tradiciones humanas para justificar la anulación de la voluntad de Dios y actuar en contra de su voluntad, aunque espúreamente pensemos actuar en su nombre (cfr. Mc 7,1-13). La revelación de Dios es, pues, todo menos ingenua por lo que toca a la pecaminosidad humana.

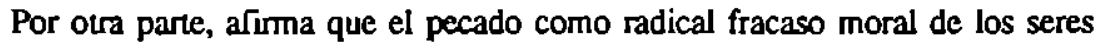
humanos no es su úlima posibilidad, que también para el pecador hay una buena noticia, un futuro abierto con posibilidades, exprésese esto en términos de salva- 
ción, perdón o redención.

Ambas cosas son claras y pertenecen al núcleo de la realidad cristiana, con lo que ésta se separa tanto de la ingenuidad como la desesperación. Pero en lo que ahora queremos insistir es en la mysiagogía del mismo Dios para llegar a comunicar ambas verdades, en el modo concrelo cómo, a través de Jesús, desenmascara el pecado del pecador y le anuncia la salvación. En forma de tesis, podemos afirmar que en la revelación de Dios en Jesús la palabra inmediata es sobre la salvación, que, como hemos dicho varias veces cilando a Rahner, Dios ha roto para siempre la simetría de ser posiblemente salvación o posiblemente condenación. Lo suyo propio es ser salvación, con lo cual el descnmascaramiento de la verdad del pecado del hombre se hace con vistas a la salvación, y, además, desde la salvación. Lo que sea pecado, desde Jesús, se comprende desde el perdón, más que éste desde aquél. Esto para nada quila gravedad a la realidad del pecado, pero la mystagogía para que se llegue a reconocerlo y en toda su gravedad acaece desde el perdón. Y no se piense que ello facilita las cosas, pues el ser humano puede preferir retener lo suyo propio, aunque sea su pecado, a ser liberado de él, si el precio a pagar es ser perdonado gratuilamente.

Esto, muy brevernente, es lo que aparece en forma concreta en el trato de Jesús con los pecadores. Ya aludimos antes a que Jesús aparece de diversa forma ante el pecador-opresor y ante el pecador-oprimido, exigiendo conversión y reparación a los primeros y exigiendo le en la bondad de Dios a los segundos. Puede añadirse también que la mystagogía de Jesús hacia el reconocimiento del propio pecado usa diversas formas: mystagogía sapiencial, pues de nada sirven las riquezas a la hora de la muerte, o escalológica, pues mejor es entrar en el reino de Dios sin mano o sin ojo, que ir al fuego del infierno. Pero su mystagogía fundamental es estrictamente teologal: Dios es de tal manera que está esencialmente inclinado al perdón, sale a buscar al pecador y en el encuentro con él consiste su alegría, lo cual - en principio - sirve para todo lipo de pecador, como se mucstra en el trato de Jesús con diversas personas y en sus parábolas. Lo que hay que analizar es qué significa "perdón"en el trato de Jesús con los pecadores.

En dos escenas sinópticas (Mc 2,5; Lc 7,48) aparece que Jesús "pcrdona" pecados. Estas escenas de perdón, sin embargo, no son reconocidas como históricas por los exegetas, pero sí lo es el hecho de que Jesús acogiese a los pecadores. Esta es una constalación histórica, pero -además, en nuestra opinión-ayuda a comprender mejor el perdón que otorga Jesús y la mystagogía de Dios con respecto al pecador. Las escenas de "perdonar pecados," en electo, pudieran desplazar el acento al poder que tuviera Jesús para absolver pecados y sugerir que el perdón que ouroga Jesús es el perdón-absolución. Esto en sí mismo ya sería importante, pero no introduciría en lo central, pues el perdón absolución pudiera presentar a Jesús (y a Dios) en último término como jucz, todo lo justo y comprensivo que se quiera, pero como juez al fin y al cabo. En esta concepción, pecador y juez, perdonado y perdonador, seguirían permaneciendo ajenos el uno al otro; y aunque sea consolador encontrar a un juez que absuelva, 
no se habria roto la simetria en Dios antes apuntada y, muy probablemente, permaneceriamos en la concepción "previa" de pecado y de perdón.

Pero en los evangelios, más que la absolución aparece la acogida de Jesús al pecador; más que el perdón-absolución aparece el perdón-acogida. Y esta diferecia es crucial. La acogida incluye la absolución, pero es mucho más que eso. Es el amor primigenio de Jesús (y de Dios) que sale a buscar al pecador, sin esperarle como juez, aunque fuese todo lo juslo y benévolo que se quiera; que muestra misericordia antes que justicia; que ofrece dignidad y futuro a quien se siente sin posibilidades.

Lo que esto significa para nuestro propósito —ofrecer una mystagogia en el misterio del pecado- es que en la dialéctica pecado-perdón el polo teologal más primigenio está en el perdón. Cierto es que una noción previa de pecado puede y dcbe decir ya mucho acerca del perdón; pero el Nuevo Testamento posee una lógica distinta. En palabras de Rahner "sólo el perdonado se sabe pecador." La acogida del perdón es lo que descubre a cabalidad el hecho de ser pecador, lo que da fuerza para reconocerse como tal y para cambiar radicalmente. La conversión tan radicalmente exigida por Jesús viene precedida de la oferta del amor de Dios. No es la conversión lo que va a exigir que Dios acoja al pecador, sino, a la inversa, es la acogida de Dios lo que va a hacer posible la conversión. Y no se piense que con esto se trivializa la realidad pecaminosa de los seres humanos, pues éstos - -ipificados en el fariseo- prefieren aferrarse a lo suyo propio, aunque fuese pecado, que liberarse de ello si la liberación les es concedida gratuilamente y no se les adjudica como obra propia.

Esto que aparece de forma historizada en los evangelios es también lo que en definitiva dicen las afirmaciones más sofisticadas en otros escritos del Nuevo Testamento. Pueden parecer muy elevadas las teologías que presentan la cruz de Jesús como perdón del pecado y muy apreciadas por la teología posterior porque parecen dar la impresión de "explicar" lo que es el pecado, lo que es el perdón y las condiciones bajo las cuales se puede otorgar éste. La cruz de Jesús podría ser entendida como sacrificio expiatorio o muerte vicaria por los pecados de los hombres. Pero estas afirmaciones, en cuanto explicaciones, no van a lo central, pueden ser engartosas y ticnen la peligrosidad de traer a Dios ante el tribunal de la razón humana que le dicla cómo ha de perdonar. ${ }^{3}$

La única "explicación" que en definitiva da el Nuevo Testamento para el perdón es el amor de Dios. La entrega en la cruz es la expresión de ese amor. Y si Dios ha amado hasta tal extremo a los seres humanos, entonces su última palabra no es de condenación, sino de salvación. Las afirmaciones del Nuevo Testamento no hacen en el fondo más que expresar en lenguaje transcendente lo que los evangelios dicen de forina sumamente sencilla y clara: Dios se ha accrcado a este mundo de pecadores para salvar, no para condenar. Ese acercamiento es iniciativa suya y no respucsla a ninguna acción de los hombres. Ese acercamiento es lo que hace creíble el amor de Dios ante los hombres y umbién -y 
esto es lo que muestran las afirmaciones transcendentes del Nuevo Testamentolo que le deja a merced de los hombres.

En la cruz de Jesús, como acontecimiento transcendente, se revelan simultáneamente la suma gravedad del pecado - llegar a dar muerte- y el sumo amor de Dios, el cual no ha tenido mejor camino para mostrarse que el de mantener su amorosa cercanía hasta el final, hasta la murte de Hijo. La "acogida" histórica de Jesús de Nazaret a los seres humanos aparece aqui como "cercania" absoluta a los seres humanos hasta el final. Ese Dios absolutamente cercano, que no hace ni siquiera de la cruz pretexto para dejar de ser cercano, es el Dios que puede pronunciar una irrevocable palabra de amor hacia los seres humanos. Y cuando éstos escuchan en verdad esa palabra de amor no necesitan ya que alguien les hable de un posible perdón-absolución de parte de Dios. Se saben amados por Dios, incondicionalmente; se saben acogidos por Dios; se saben acercados a Dios en el absoluto acercamiento de Dios a ellos.

La revelación dice, en sumn, que los seres humanos son pecadores, que el pecado es sumamente grave; pero dice también que hay posibilidad de perdón. Más aún, que el ser perdonador no es una entre las posibles características de Dios, sino lo que expresa su propia esencia. Y dice que a través del perdón el ser humano puede llegar a conocerse como realmente es: como pecador y como salvador.

\section{El perdón como liberación}

Lo dicho muestra que el perdón es central en el Nuevo Testamento, pero además, que en cuanto el perdón es acogida y no mera absolución, el perdón es formalmente liberador.

La acogida-perdb́n que otorga Jesís en las narraciones evangélicas no es algo sólo beńffico, sino liberador. En esas narraciones aparece una importante expresión de esa liberación en el contexto del desprecio y la marginación social - puede pensarse que, a veces con razón, y muchas veces hipócritamente- a que estaban sometidos los pecadores. El que Jesús se dirija a ellos, les acepte en su companía, coma con ellos, es una clara expresión de la superación de la segregación social. Pero, sobre todo, Jesús les devuelve la dignidad perdida. J. Jeremias describe de la siguiente forma lo que debio ocurrirle a Zaqueo: "El hecho de que Jesús quiera albergarse en su casa, en casa de este hombre despreciado y a quien todos evitaban, es para él inconcebible. Jesús le devuelve el honor perdido, hospedándose en su casa y partiendo el pan con el".4 El perdón-acogida abre un futuro nuevo y positivo al pecador, le abre espacio social ante otros y le abre un espacio intemo ante sí mismo. Jesús puede decirle en verdad: "vete en paz."

Hay otro aspecto en la liberación que otorga el perdón-acogida que han notado con sorpresa los exegetas. En varias de la escenas de curaciones y en una de las escenas de perdón Jesús pronuncia estas sorprendentes palabras finales: "Tu fe te ha salvado." Con ello dice Jesús que la acogida al pecador ha originado una verdadera renovación intrínseca en la persona, que el perdón no queda como algo 
bueno, pero en definitiva como algo extrínseco a la persona En el "tu fe te ha salvado" aparece la fuerza salvadora de Dios que quiere y puede lograr la transformación real de la persona. Y aparece lo que podemos llamar la suma delicadeza de Dios que viene a decir "ú puedes." Esa delicadeza supone decir que, indudablemente, Dios ha perdonado al pecador, pero en la acogida no le interesa tanto a Dios atribuirse a si mismo un "triunfo" cuanto animar y convencer al pecador de que él puede cambiar, de que sus posibilidades son mayores de lo que él pensaba.

La conversión no es entonces cosa puramente pelagiana, sino posibilitada; pero es ante todo cosa real. Es realmente el ser humano el que queda cambiado, justificado y liberado.

Esa acogida libera al hombre de su pecado, pero además lo libera de sí mismo, de lo que considera ser su verdad. Ya hemos alirmado que no es cosa fácil el llegar al reconocimiento del propio pecado. No lo es porque el pecado posee la innata tendencia a ocultarse así mismo, a hacerse pasar incluso por lo contrario; por ello en Juan el pecador es el "mentiroso." Y no es fácil porque un reconocimiento cabal del propio pecado - -sin que apareciese la posibilidad de perdónllevaria lógicamente al ser humano a la paralización, a la angustia sobre sí mismo. Sin embargo, saberse pecador en el acto de saberse perdonado, facilita el reconocimiento del propio pecado porque éste no es percibido ya sólo en su lado oscuro y esclavizante, sino tambien desde la luz del perdón. Y esto es lo que puede quebrar la hybris humana que preliere retener lo suyo propio, antes que desdecirse de sI mismo, quebrar la avidez con que el ser humano se apega a sí mismo (superada por Cristo en la afirmación transcendente de Filipenses 2,6). El perdón es entonces liberación de la mentira sobre sí mismo con la cual el ser humano quiere oprimir su verdad. 5

El perdón libera por último al ser humano para reconocer a Dios tal cual es, en su esencial dimensión de gratuidad y parcialidad. Correlativa a la tendencia a querer aparecer justo ante Dios está la visión de Dios que se muestra en justicia. Pero aceptar el perdón es también el modo de a irmar la verdadera realidad de Dios como gratuito y parcial. Lo que la teología recalca con respecto a la relación Dios-pobres, hay que recalcarlo también con respecto a la relación Dios-pecador. Ambas cosas introducen a la verdadera realidad de Dios.

No acepar eficazmente la posibilidad de la acogida perdonadora de Dios, ignorarla o considerarla como de menor importancia, significaría desconocer a Dios. No aceptar, como algo central en Dios, la alegría última en su acogida al pecador significaría en úlumo término no creer en Dios. Pero, a la inversa, dejarse acoger por Dios perdonadoramente significa creer en Dios y esclarecer en qué Dios se cree.

El perdón-acogida es, por lo tanto, algo bueno y también algo formalmente liberador. El perdón es un benelicio, pero es también liberación de la mentira con que queremos oculúamoslo, de nosotros mismos y de nuestra visión de Dios. 


\section{Liberación del pecado personal y erradicación del pecado his- tórico}

Todo lo dicho es una verdad central en la revelación de Dios y lo es, además, de una manera sorprendente: el difícil reconocimiento del propio pecado y la difícil realización de la conversión proviene en último término del perdón como luz sobre la propia verdad y como fuerza para la propia conversión. En cuanto verdad, no se la puede ignorar ni se la puede asentar con una lógica que provenga de otra fuente más allá del hecho mismo. Simplemente así es Dios.

Teológicamente, sin embargo, debe reflexionarse cómo esta verdad central se integra dentro de la reflexión de la teología; y en este caso, de la teología de la liberación. Más en concreto, qué dice esta verdad a una teologla que hace como finlacidad específica suya la erradicación del pecado histórico estructural, cómo realionar el dejarse perdonar personalmente por Dios con la práctica del reino para erradicar el antirreino. Digamos de antemano que no se trata aquí de manipular una verdad en favor de otra, sino de afirmar ambas como verdades centrales, desde el presupuesto - ciertamente de la fe, pero también desde la reflexión- de que ambas verdades convergen en la verdad de la liberación total, del ser humano y de la historia, en la llamada liberación integral.

Al preguntamos cómo la liberación personal del pecado ayuda a la liberación historica pueden surgir algunas preguntas críticas. Puede decirse que lo antes dicho, con ser verdad, es excesivamente utópico (ni el mismo Jesús hubiera tenido mucho éxito), es excesivamente individualista e históricamente pudiera desembocar incluso en una actilud escapista. Y creemos que así es, que lo dicho tiene su peligrosidad, que cualquier verdad, por central que sea, puede ser elevada a única verdad, lo cual es otra manifestación de la concupiscencia humana; pero creemos también que las verdades plurales en que se manifiesta la única verdad de Dios convergen. Por ello creemos a priori que puede y debe haber una relación positiva y mutuamente complementaria entre perdón personal y erradicación del pecado hislórico; y, a posteriori, que esa relación puede iluminarse en la realidad histórica.

A priori hay que afirmar que la lógica de la revelación prohíbe hacer de lo "propio" algo central y úlimo, aunque eso fuera algo tan importante como el propio perdón y la propia salvación. Ni el mismo Dios hace de lo suyo propio la central, sino que se ha mostrado como Dios-para-los-otros; más específicamente, como Dios-para-los-débilcs. De ahí que sea muy lógico - con la lógica de la realidad, más que con la lógica del puro concepto- que pueda esperarse que el perdonado, el que se ha dejado acoger por Dios, no haga de ello lo central y lo úlumo; sino que, más bien, el acogido por Dios se torne en acogedor, el perdonado, en perdonador.

Esta lógica es la de la primera carla de Juan: del ser amados por Dios se concluye el amor a los hermanos; y la de la teología de la liberación, como la ha 
expuesto G. Gutiérrcz: "amados para amar," " libcrados para liberar."6

Dicho ahora de forma histórica hay que preguntarse no sólo por el qué, sino por el para qué del propio perdón, de la propia liberación. Si no hubiese un para qué que trasciende al propio perdonado, el perdón personal quedaría encerrado en el propio perdonado, lo cual va contra la lógica última de la revclación de Dios. Si cl perdonado - ahora de otra forma- volviera a retener su perdón, volvcría a convertirse en el ser humano egocéntrico, se convertiría - según la lógica cristiana- en el desagradecido y se podría dudar incluso de si en verdad se ha dejado acoger perdonadoramente por Dios.

De qué libera el perdón al perdonado, ya se ha dicho. Para qué lo libera, es lo que hay que analizar. Lo libera, en primer lugar - por la naturaleza histórica del perdón-, para a su vez poder acoger y perdonar a ouros. Pero, más en general, lo libera para realizar positivamente el amor de Dios para con el mundo, del cual el ha tenido experiencia personal. Esc amor de Dios tiene como elemento esencial el ver al mundo tal cual es, en su verdad, no en su mentira; y para realizar, en la verdad de ese mundo, la voluniad de Dios. La liberación del pecado personal, como el dejarse ser acogido por el amor de Dios, lleva entonces a hacer presente en el mundo el experimentado amor de Dios. Sólo que al nivel histórico mundanal, "perdonar" el pecado del mundo es "erradicarlo."

En concreto hay que preguntarse qué aporta el perdón personal a la erradicación del pecado histórico. Sustancialmentc aporta la posibilidad de una mejor praxis libcradora, en su dirección, en su intensidad y en sus valores; lodo lo cual pucde estar influyendo en personas y en grupos liberadores.

El perdonado, como hemos visto, es liberado de su propia mentira. Pero si el ser "mentiroso" es la afirmación antropológica formal sobre el pecador, según el mismo Juan, su contenido material es ser "asesino." La dureza de estas palabras (y su necesaria comprensión analogica) no debe restar importancia a la intuición fuadamental: el ser humano pecador realiza simuláneamente un doble viciamiento del verum y el bonum, un doble sometimiento de la verdad a través de la mentia y del bien a través del dar muerte, una doble negación de su creaturidad de ser -mentirosamente- más de lo que es ante Dios (el pecado origianl de Adán) y de ser -injustamente- más que el hermano (el pecado orginal de Caín). Puede discutirse teóricamente cuál de esos dos polos es antropológicamente más primigenio; pero al menos hay que aceptar su dialéctica entre el "mentiroso" y cl "ascsino," entre defenderse de Dios y ofender al hemnano.

Con esto quiere decirse que el pecado es "mentira," pero tiene un contenido: "dar muerte." En el perdón se hace al ser humano sabedor de su mentira y del contenido de su mentira; de la gravedad de lo uno y de lo otro. Y aunque esto parezca un mínimo, no lo es: se le abren los ojos para saber lo que es y lo que hace, la suma maldad de su hybris y del producto histórico de ella. Y en cuanto estos sabcres son proporcionados en el perdón, se hace posible reconocerlos y 
mantenerlos en toda su crudeza y así vivir en la verdad: vivimos en un mundo que da mucrie, y en ello está su verdad más radical.

La tcología y piedad tradicionales han mantenido siempre que para saber qué es pecado hay que ponerse ante Cristo crucificado: él es el perdonador, pero él cs también cl ofendido de mancra precisa: aquél a quien han dado muerte. Hoy también, el perdonador abre los ojos para saber de qué hay perdón: de la responsabilidad en la continuada crucifixión de pueblos enteros.

El poder ver con ojos nuevos la verdadera realidad del mundo, el poder mantenerla a pesar de su tragedia, el poder percibir qué es aquello a lo que Dios dice un radical no, es (lógicamente) el primer fruto de dajarse realmente perdonar por Dios.

El perdonado gratuilamente es el agradecido. Ese agradecimienso de saberse acogido es el que lleva al descentramiento de uno mismo, a la acción generosa, a vivir y desvivirse para que el experimentado amor de Dios sea una rcalidad histórica en este mundo. La lógica del perdonado-agradecido - aunque siempre haya que precaverse de los entusiasmos de los neoconversos-es la que abre el corazón a una práclica salvífica c histórica sin límites. Así aparece prototípicamente en Pablo, quicn sc siente amado por Cristo y hace de su vida total y absorbente apostolado en favor de los demás hasta el extremo de ignorar ya su propia salvación para concentrase en la salvación de sus hermanos. Así aparece en san Ignacio de Loyola, a quien el agradecimiento de saberse acogido y perdonado por Dios lo lleva a preguntarse ante Cristo crucificado "qué hago" y "qué voy a hacer" por Cristo. Esas preguntas son la expresión histórica más acabada del agradecimiento. No hay sólo un responder agradecidamente, sino un corresponder generosamente a la realidad de aquel que lo acogió y lo perdonó.

De ahí que el experimentado amor de Dios mueve a hacer rcal ese amor en el mundo y a hacerlo con generosidad sin límiles; en el lenguaje de san Ignacio, a actuar para la "mayor" gloria de Dios.

Estas experiencias de Pablo y de san Ignacio tienen hoy su traducción histórica. El perdonado a quien se le han abierto los ojos sobre la muerte que impera en el mundo de hoy y su participación en ella (con todas las analogías del caso) tiene que poner a producir -y así ocure- su agradecimiento. Como San Ignacio ante Jesús crucificado se pregunta ante los pueblos crucificados: "¿qué he hecho yo para crucificarlo? ¿Qué hago para que los descrucifiquen? ¿Qué debo hacer para que ese pueblo resucite?"7

El perdón, pues, no queda encerrado en el perdonado; se deborda en agradecimiento, y éste en la práctica histórica de la misericordia (con todas las mediaciones coyunturales y estructurales, de tranformaciones objetivas y de acompañamiento en el sufrimicnto y la esperanza...).

El perdonado aporta a la liberación el recuerdo de la propia pecaminosidad, real y simpre posible, de quienes orientan su vida hacia una práctica liberadora. Este recordatorio no es, de nuevo, masoquista; es un recordatorio salvífico, como lo 
es la "memoria peligrosa" de Jesús, pues, aunque exigente, nos retrourac a la verdad, a la honradez con lo real. El recuerdo del propio pecado genera una humildad frucúfera, hace más lácil reconocer (y remediar) las limitaciones a las cuales están sujectos los procesos de liberación, por necesarios, buenos, y justos que scan; hace más lácil percibir (y remediar) los dogmatismos, protagonismos, reduccionismos, que inevitablemente gencran, también, esos procesos como subproductos negativos. ${ }^{8}$ En una palabra, el recuerdo del propio pecado - recuerdo, en cuanto honrado y no ncurótico, posibilitado por el perdón- ayuda a minimizar la hybris que se introduce también en la práctica de la liberación. "Hacer la revolución como un perdonado," en las afortunadas palabras de González. Faus, ${ }^{9}$ es un bien para la práctica de la liberación, para que ésta sea más humana y humanizante y esić alejada de los peligros que la acechan e incluso para que -a la larga - sca más opcrativa.

\section{Los pobres y oprimidos como mediación histórica del per- dón acogida}

El haber recalcado que el pecado es redescubierto precisamente desde el perdónacogida exige una obvia rellexión sobre su mediación histórica, pues si ésta no se diera, vano scría todo lo dicho anteriormente. Y desde cl punto de vista de la liberación exige una reflexión sobrc si y qué papel jucgan los pobres y oprimidos en ese perdón; es decir, si en cuanto ofendidos son perdonadores y en cuanto perdonadores revelan la magnitud de la ofensa que se les inllige.

Lo que aquí queremos afirmar es que en la historia de la Iglesia y de la teología se han elaborado muchas mediaciones históricas del perdón-absolución - sacramentales o no estrictamente sacramentales-, pero queda pendiente la pregunta por la mediación del perdón-acogida, sobre todo de aquellos pecados -y del pecado estructural en sí mismo-que oprimen y dan muerte generalizada. Y nuestra tesis, obvia en su formulación, pero nada obvia en llevarla a la práctica consecuentemente, es que los que hoy ofrecen -cstructuralmente y en expresiones concretas- el perdón-acogida son los pobres y oprimidos de cste mundo.

Elevar a los pobres de este mundo a mediadores del perdón-acogida no tiene nada de retórico ni, en principio, debiera ser sorprendente.En la reflexiớn teológica biblica y en la actual reflexión teológica sistemática es una constante presentar a los pobres - y como colectivo de pobres- en aspectos cruciales de la revelación: la manifestación de Dios, inmediata y parcialmente, a un pucblo oprimido, la salvación proveniente de cse mismo pucblo en cuanto carga con el pecado del mundo, la exigencia ética fundamental a servir a los pobres, la capacidad de los pobres para exigir la conversion y, en las bellas e inauditas palabras de Puebla, su capacidad evangelizadora. A estas conocidas y centrales afirmaciones, Juan Pablo II ha añadido otra muy importante: en el día del juicio los pueblos del tercer mundo juzgarán a los pueblos del primer mundo. Dicho en lenguaje teológico, el hijo del hombre, presente ya hoy en los pobres, juzgará en el juicio escatólogico a través de los pobres. 
Este verdadero theologoumenon de Juan Pablo II puede y debe y completarse de la siguiente manera. Los pobres de este mundo son quienes cargan con el pecado dcl mundo; son por ello los verdaderamente ofendidos y sus acusadores. Pcro, además, son ya los que juzgan al mundo y los que ya pueden olorgar el perdón-acogida a sus opresores. Que esto último sea una realidad es algo sobre lo quc no caben especulaciones, sino algo que debe ser constatado. Pero lo que interesa añadir es que si no existiese tal perdón-acogida de parte de ellos, vano scría buscar el perdón, tal como se ha descrito, en este mundo. Se podría seguir tenicndo noticia acerca de la actitud perdonadora acogedora de Dios, pero faltaría la mediación histórica para ello; y eso por lo que toca al más grave de los pecados, y no a los de menor monta.

¿Es real el theologoumenon de que los pobres son los que nos ofrecen el perdón-acogida? Ya hemos dicho que eso se decide en la realidad histórica y esa es la que debe ser investigada. En nuestra opinión hay suficiente experiencia histórica de ello, aunque desconocemos si ese perdón-acogida acaece en todas partes y de igual forma. En la experiencia centroamericana hay muestras de esa acogida-perdón que queremos presentar en la siguiente fenomenología.

Cuando alguien se acerca a un relugio, a un poblado desolado por la guerra, a una comunidad que ha sufrido persecuciones y martirios, una de las cosas que más llama la atención es la diferencia entre lo que lógicamente pudiera ocurrir en el encuentro con los pobres y oprimidos y lo que realmente ocurre. Lógicamente -scgún la lógica de la razón natural y la lógica del perdón-absolución-pudiera ocurrir que los pobres rechazaran la visitas de quienes estructuralmente pertenecen al mundo de sus opresores, de que les recibieran con recriminaciones por haber llegado tarde -después de aftos y siglos - y por llegar mal o a medias - sin una decisión total a comprometerse con ellos. Pudiera ocurrir que los recibieran con una actitud puramente pragmática de aprovecharse de sus servicios en lo posible o con la actitud del perdón-absolución según la regla del tanto cuanto: tanta remisión de pecados cuanta sea la reparación. Pero no es eso lo que generalmente ocurre - aunque puedan a veces estar presentes algunos de esos elementos-, sino todo lo contrario. Los pobres descritos les abren sus puertas y corazones, les cuentan sus aflicciones, les dan de lo poco que tienen, les agradecen y muestran su gran alegría por su visita y les piden que no se olviden de ellos y cuenten lo que han visto cuando regresen a sus lugares.

¿Qué es lo que ha ocurrido en este encuentro entre los pertenecientes, estructuralmente, al mundo oprimido y al mundo opresor? No cabe duda de que los pobres han acogido a quienes pertenecen al mundo de sus opresores y que - sin decirlo y sin ellos saberlo- les han otorgado el perdón-acogida. En ese encuentro, como reconocen muchos, los visitantes han hecho la experiencia antes descrita: simultáneamente se saben pecadores y perdonados, se saben en su verdad y en su posibilidad, y reorientan su vida desde el "qué voy a hacer."

Esta fenomenología puede parecer idealizada; pero no lo es, pues en la expe- 
riencia descrita no hay ningún melifluo lirismo, sino suma gravedad y seriedad en los acogidos y en los acogedores. Puede parecer una extrapolación injustificada de lo que pudiera llamarse "ejemplos piadosos;" pero no lo es, pues sea cual fuere la magniud real de la experiencia, ésta acaece quasi ex opere operato, es decir, en base a la estructura de la realidad y no a la pura intencionalidad; la experiencia descrita no es sólo ejemplo sino typos repetible. Puede parecer paradojica y escandalosa; y lo es, pero no más que otras afirmaciones que hoy se repiten teológicamente: que en los pobres está Dios, que los pobres son los portadores de la salvación, etc.

Los pobres son, pues, la mediación histórica del perdón-acogida de Dios. Y si es verdad que desde el perdón se posibilita el reconocimiento del propio pecado y se obtiene la fuerza para una práctica contraria al pecado, se está diciendo entonces que hoy lambién hay posibilidad de reconocer el pecado del mundo y de la decisión a erradicarlo. Pero, como en el caso del pecado personal, hay que afiadir que eso tampoco es fácil: el mundo opresor no quiere dejarse perdonar y por ello le es tan sumamente diffcil saberse en su verdad.

Esta afirmación fundamental de que el perdón-acogida proviene de los pobres de este mundo sirve también para solucionar $\longrightarrow$, al menos, sacar a la luz- un problema estrictamente eclesial pocas veces abordado: quién perdona el pecado de la Iglesia como tal. Sabido es que desde sus inicios la Iglesia ha reconocido la existencia de pecadores individuales en su seno y ha diseffado diversas formas de perdón para el pecador individual. Pero con el redescubrimiento del pecado de la Iglesia como tal, al tomar en serio que la Iglesia es estructuralmente santa y estructuralmente pecadora (la casta meretrix) -como lo muestra Rahner ${ }^{10}$ en base al Vaticano II- surge la pregunta de qué hacer con ese pecado estructural de la Iglesia, pues para examinarse y arrepentirse de él, satisfacer por él y ser absuelto de él no basta el sacramento de la penitencia.

Esta pregunta, de nuevo, no es retórica. De no abordarla, la Iglesia estarla afirmando que no toma en serio la dimensión estructural de su pecado, y las límidas palabras que ocasionalmente pronuncia sobre su propio pecado no pasarían de ser nutinarias y vanas. Es decir, vano es repetir que existe pecado en la Iglesia si no se menciona a los ofendidos y, por lo tanto, a sus posibles perdonadores.

En América Latina debe decirse que la Iglesia en su conjunto ha avanzado considerablemente sobre su anterior actuación secular, objetivamente en contra de los pobres; pero el no hacer radical y consecuentemente la opción por los pobres sigue siendo su más grave pecado y el erradicarlo su más grave responsabilidad. Pero para poder hacer ambas cosas tiene que estar dispuesta a dejarse perdonar por los pobres. Bellamente dice Puebla que los pobres evangelizan a la Iglesia en cuanto la interpelan llamándola a conversión y en cuanto le ofrecen la realización de importantes valores evangélicos. Lo que aquí se propone es dar un paso más y considerar a los pobres como perdonadores, como los que le proclaman el evangelio del perdón-acogida. Este paso es crucial y nada fácil. Si no se da, si no se 
mira a los pobres como los perdonadores, tampoco se les mirará realmente como los ofendidos y la Iglesia seguirá encubriendo a sí misma su propio pecado. El paso es difícil, pues supone superar la hybris de la Iglesia, hybris tan real como la de otros grupos sociales y como la del individuo; y hybris que le imposibilitará ponerse delante de Dios como él realmente es: acogedor y perdonador. Desde un punto de vista histórico pervivirá el triunfalismo eclesial, según el cual nadie tiene que enseñar a la Iglesia nada realmente serio y nadie tiene que perdonar a la Iglesia nada realmente grave.

Pero, a la inversa, si la Iglesia se deja también perdonar por sus ofendidos, será capaz de reconocerse tal cual es — ambién en su dimensión pecaminosa-, será capaz del excenuricismo radical hacia el otro, el pobre; será capaz de ponerse ante el verdadero Dios, exigente y misericordioso, dejándolo ser Dios y sin que su hybris le dicte de anternano cómo deba manifestarse, y será capaz de vivir, en la dura realidad, el gozo de saberse acogida y de vivir en comunión, con Dios y con los pobres de este mundo.

\section{Conclusión}

En América Latina existe el mysterium iniquiratis y en esa realidad hay que proclanar el mysterium salutis. Existe el pecado, de mil formas, como hybris y como opresión, como mentira y como asesinato; y en esa realidad hay que anunciar el evangelio de que es posible su superación y de que es absolutamente necesaria su erradicación. Lo que hemos querido decir en estas páginas es que el pecado, en todas sus formas, es un mal, es lo que da muerte al espíritu y a la came de los seres humanos; que el pecado, además de ser un mal, es también esclavizante, y por ello su superación es formalmente liberación; y que, entre la diversidad de mystagogias para reconocer la realidad del pecado y la motivación a su supcración, una no debe faltar por ser central en la revelación de Dios: la disponibilidad a ser acogidos-perdonados.

Esto último es más fácil de ser captado en el caso del pecado y del perdón personales, pero es también necesario introducirlo como uno de los elementos estructurales en la tarea de erradicar históricamente el pecado del mundo.Esta tarea exige obviamente otros elementos, como son las prácticas liberadoras. Para motivar a los opresores a que dejen de serlo, se deberá usar de todos los medios persuasivos y cocrcitivos, apelar a las conveniencias políticas y a la amenaza de que la situación del tercer mundo pueda llevar al desastre de todos los mundos. Pero, como un aporte específicamente cristiano a la liberación, hay que seguir proponiendo también la posibilidad del perdón que Dios sigue ejerciendo a través de los oprimidos de estc mundo. Históricamente puede pensarse que esto no tenga mucho éxito, pero como lodo principio utópico puede principiar realidades positivas: el reconocimiento del pecado del mundo y la disponibilidad a bajar a los crucificados de su cruz.'2 


\section{Notas}

1. Vease lo que hernos escrito en "America Latina: lugar de pecado, lugar de perdón", Concilium. marzo 1986, 220-225.

2. Es este un hecho notable que no se debe pasar por alto a la hora de diseñar ja acción pastoral de la Iglesia y de insistir en que la opeión por los pobres debe ser preferencial y no exclusiva. Los evengelios no tienen empacho en mosirar que a Jesús le fue difícil cambiar a los poderosos, salvo en el caso de Zaqueo, y, más moderadamente, en el de José de Arimater.

3. Esto se sgrava con Anselmo y con los anselmianismos que, una y otra vez, reaparecen en la teologín (qué deban significar los pobres para que sea lógica la actitud de Dios hacia ellos; o, en tono menor, la conveniencia de que el sacerdoce sea varón, por poner sólo dos ejemplos).El probleme no esuí en concepualizar le revelación, ni siquiera en usar algunos antropomorfismos inevitables, sino en dictar a Dios cómo deban ser las cosas - aunque eslo se haga después de courridas- y no dejarle ser Dios.

4. Teologla del Nuevo Tesiamenso I (Salamanca, 1973) 187.

5. La hybris es meical arrogancia que, une vez llegada a ser, esclaviza al ser humano, y, por lo tunlo, necesile formalmente de una liberación. Y la hybris, además tiene una génesis, es algo - b que se llega a través de un proceso, aunque esté de algún modo presente ya en el inicio. Pablo lo describe, sintéticamente, como "proceso de autoengaño sutil... de divinización del yo a traves de la divinización del deseo," hasta llegar a la idolatría con su contrapartida esclavizante expresade entroponórfiermente en el "Dios los entregó a sus descos." En san Ignacio de Loyola el proceso es bien preciso: riquezas, honores y soberbia (la arrogancia radical) y de ahí a todos lon vicios. P.Ricoeur describe asl he hybris, tal como le entendían los griegos: "el éxito engenda el maia del 'siempre mis y más' -es decir, la pleonaksín-; y ul alvidez. engendra la complecuncia propia, del mismo modo que ersa engendra la arrogancia." El ikgar a la hybris es alcanzar un esiado de escleviund radical, es arribar al estedo de pecado, de lal modo que para los griegon "ere en el único pecado que castigaban los dioses." La fe cristians comparte la radical negatividad de la hybris y de su realidad formalmente eselavizante que necesita no sólo de abeolución, sino de verdedera libención, an lo cual consiste algo central suyo: por gracia, Dios es copaz de liberamos de nosaros mismos. Para lo dicho en esta note, véase J.I. Gonzslez Faus, Projecto de hermano. Visión creyense del hombre (Santander 1987) 202-211. Los entrecomillados de este noh esun en las páginas $207 \mathrm{ss}$.

6. Beber en su propio pozo (Lime 1983).

7. I. Ellecurta, "Las Iglesies latinoamericanas interpelan a la Iglesia española," Sal Terrae, marzo 1982, 219-230.

8. Vése nuestro libro Liberación con espírisu ( San Salvador 1987), especialmente pp. 9.58.

9. En ello he insistido Gonzulez Faus an op.cit., 194.200.509s.

10. Escrivos de teologia VI (Madrid 1969) 295.337.

11. Pueble, en eu Mensaje a lon pueblos de Américe Latine, dice estas palabras: "Por todas nuestras falus y limilaciones, pedimos perdón, tumbien nosocros pastores, a Dios y a nuestros hermanos en la fe y en la humanidad." Estas palabras son clarss, pero no son frecuentes. Lo normal es contentarse con palabres como "reconocemos que no siempre hemos sido consecuentes..." Lo importante no ron, por supuesto, la palebres; pero lo que parecen ocul lar éstas es el miedo a nombrnr con cleridad a lo ofendidos por la Iglesia, el miedo a dejarse perdoner por ellos o el ni agujera caer en la cuenta de ca posibilided y de esa necenidad. Las claras palabras de Puebla - l menos en una reconntrucción logica- se explican por la actitud de ponerse ante los pobres y de acepur que ellos evangelizan (Y, atiadimos nosolos, perdonan).

12. De un ejemplo no se puede secar una tesis, pero un ejemplo luminoso aclara la tesis, como es el caso de Mons. Romero. Lo que se ha dado en llamar su conversión tiene diversas raíces. Pero en nuestra opinión, la más decisiva pan mantenerlo en el cambio radical que se operó en él, en 


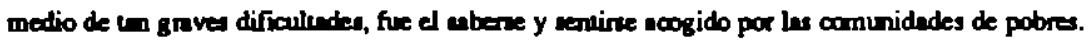
Aquelles comunidedes con la que entes de un converión avo grendes conflicas lo scogieran

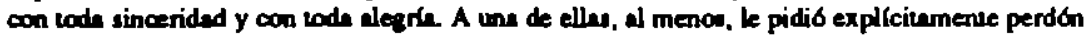
por su conducte anierior. La obre posterior de Mone. Romero fue clarumente en fovor de esas comunidades y del pueblo pabre en general; pero en la niz estil el haber sido eogido por ellas, "perdonado" de au anterior naunción. Con ello y deade ello se le iluminó su inadecuedn pastoral anterior, rocibio ecogida y consuelo, y une fortaleza sin limites para mentenerse en su mision. Y ese proceso que queda claro en lo personal de Mos. Ranero vino a formar parte de la estructura de au misión eclesial. Se dio una dieltecica entre dejarse acoger por el pueblo y lanzarse a la misión pare ese pueblo. Que reparnos, Mans. Romero no lo formulo con nuestres palabras; pero dos conocides formuleciones suyas a ello apunian con tode claridad "Con este pueblo no cuesu ser buen pastor. Es un pueblo que empuje a su servicio..." (18.11.1979). "La Iglesia está can el pueblo y el pueblo ear con la Iglesin | Grecias a Diosl (21.1.1979). 